acylated complex of Toho-1 E166A. The best correlation was observed at $T_{m}$. vs. $\ln \left(k_{c a l} / K_{m}\right)$. We have a hypothesis that the stability and/or the thermal fluctuation of the catalytic intermediate correlates the catalytic parameters quantitatively, because the results of X-ray studies showed that the poor substrate greatly reduces anisotropy of experimental atomic fluctuation of the protein atoms than that in the case of the good substrate, in crystal structures of acyl-intermediates.

\section{TA1-09 新規デフェンシンの膜構造と抗菌活性}

\section{P-032 A new strategy of defensin against Gram-positive bacteria}

Keiichi Kawano (1), Takahide Kouno (2), Naoki Fujitani (5), Mineyuki Mizuguchi (4), Tsukasa Osaki (3), Shun-ichiro Kawabata (3), Tomoyasu Aizawa (1), Makoto Demura (5) ((1) Grad Sch Sci, Hokkaido Univ: (2) Fac Pharm Sci, Toyama Univ; Dep Biochem Mol Biol \& Biophys, Minnesota Univ: (3) Dep Biol, Kyushu Univ: (4) Fac Pharm Sci, Toyama Univ: (5) Grad Sch Life Sci, Hokkaido Univ)

Big defensin is a 79-residue peptide derived from hemocytes of the Japanese horseshoe crab. It has antimicrobial activities against Gram-positive and -negative bacteria. The amino acid sequence of big defensin can be divided into an $\mathrm{N}$ terminal hydrophobic half and a $\mathrm{C}$-terminal cationic half. Interestingly, the trypsin cleaves big defensin into two fragments, the $\mathrm{N}$-terminal and the $\mathrm{C}$-terminal fragments, which are responsible for antimicrobial activity against Gram-positive and -negative bacteria, respectively. We determined the solution structure of mature big defensin and elucidated that the $\mathrm{C}$-terminal domain of big defensin adopts a $\beta$-defensin structure, while the $\mathrm{N}$-terminal domain forms a unique globular conformation. In addition, the $\mathrm{N}$-terminal hydrophobic domain undergoes a conformational change in micelle solution. We proposed that the $\mathrm{N}$ terminal domain achieves its antimicrobial activity in a novel fashion, and big defensin has developed a different strategy from other $\beta$-defensins to suppress the growth of Gram-positive bacteria. For further analysis, we determined the structure of the $\mathrm{N}$-terminal fragment of big defensin in a micellar solution, showing that the fragment peptide forms a single $\alpha$-helix structure. Moreover, NMR experiments using paramagnetic probes revealed that the $\mathrm{N}$-terminal domain of big defensin penetrates into the micelle. Here, we propose a new model for big defensin to associate with the target membrane.

\section{TA2-01＼cjkstart成熟した横紋筋における微小管と適応における役割：チューブリ} ンの分子シャペロン $\alpha \mathrm{B}$-クリスタリンの細胞内機能から

Significant roles of microtubules in mature striated muscle: Insight from correlative expression of tubulin and its molecular chaperone alphaB-crystallin

Yoriko Atomi (1), Hyunseok Jee (1), Takashi Sakurai (1), Eri Fujita-Ohto (2) ((I) The University of Tokyo, Radioisotope Center: (2) The University of Tokyo, The Department of Information and Communication Engineering, Graduate School of Information and Science Technology)

The cytoskeleton is an essential component for the cell. One of the cytoskeleton, microtubule (MT) is well characterized in mitotic cells and in vitro, while the rol of MT in matured striated muscles has not been elucidated yet. We have shown the possible role of molecular chaperone alphaB-crystallin to protect disturbance of denatured tubulin and keep MT network in the process of muscle atrophy. To understand the significance of cytoskeletal microtubule networks in striated muscles, we analyzed correlation between the content of tubulin and alphaB crystallin in a variety of striated muscles expressing different myosin heavy chain (MHC) isoforms. The content of both tubulin and alphaB-crystallin was larger in MHC-I dominant soleus muscle and in MHC-alpha dominant cardiac (atrium and ventricle) muscles; intermediate in MHC-IId dominant diaphragm and tongue muscles; and smaller in MHC-IIb dominant plantaris, gastrocnemius, masseter, psoas, and extensor digitorum longus muscles. Since the muscles of slow type MHC (MHC-I/alpha) show the most economical features in their function and metabolism, which suit for continuous activity required to sustain posture and blood pumping, the present results afforded additional support to our hypothesis that microtubule networks transduce mechanical environmental demands to morphological and biochemical responses that eventually evolve adaptive transformation in the function and metabolism of the mature muscles. The comparison of tubulin/alphaB-crystalline ratios across the muscles of varied MHC isoforms further suggested that mechanical stress fluctuating at the rhythmic frequency of walking and breathing efficiently activates the hypothesized dynamic function of microtubules.

\section{TA2-02＼cjkstart平滑筋ミオシンIによるFアクチン束化のメカニズム} Mechanism of F-actin bundling by smooth muscle myosin I

Yoh Okamoto (1), Tatsuya Kawai (1), Kohei Morimoto (1), Masahiro Kuragano (1) ((I) Division of Applied Science and Engineering, Muroran Institute of Technology)

Myosin I is a large family of unconventional myosins. We have found and characterized myosin I in aorta smooth muscle which has homologous amino acid sequence of myosin IB of bovine brain and adrenal gland. (Hasegawa et.al;1996,1998). The aorta myosin I consisted of equimolar amounts of $110 \mathrm{kD}$ heavy chain and calmodulin. The myosin I could bind another calmodulin at the most in the presence of exogenous calmodulin. Since architecture of contractile system in smooth muscle cell is not well understood, we have examined a possible contribution of the aorta myosin I for alignment of F-actin filaments into the bundle. The properties of F-actin bundle with aorta myosin I was characterized as follows. (1) The bundle formation is a process which depends on electrostatic interaction of proteins. I.e. increasing of ionic strength blocks appearance of F-actin bundle with bound myosin I. (2) Either flexibility or site specific inhibition on $\mathrm{F}$-actin regulates the myosin I dependent bundling. i.e. Tropomyosin inhibits the F-actin bundling in a saturable manner. (3) Another Factin binding site located in the tail region of myosin I. i.e. The F-actin bundling could be inhibited by phospholipids in a specific manner such as in the presence of phosphatidyl glycerol but not with phophatidyl choline. This is consistent with our previous findings that phosphatidyl glycerol bind to the tail of myosin I but not with phosphatidyl choline (ibid; 1996). It is keen to find out the switching mechanism of binding partners, F-actin or phospholipids, for elucidation of the role of $\mathrm{F}$-actin bundle in smooth muscle cell.

\section{TA2-03 骨格筋ミオシンの尾部の脆弱部位の予測}

Prediction of fragile points of skeletal myosin rods

Mieko Taniguchi (1), Hideki Tanizawa (2), Ghimire Ganga D. (3), Sigeki Mitaku (2) ((1) Depertment oBiotechnology and Biomaterial Chemistry, Nagoya University: (2) Dpartment of Aplied Physics, School of Engineering, Nagoya Unversity: (3) Reseach Centre Juelich, Institute of Neuroscience and Biophysics, Molecular Biophysics)

It is reported that muscle and non-muscle myosin rods have a flexible region in their coiled coil region. Usually these regions were highly conserved; therefore it is considered they play an important role in muscle contraction. Here we show that it is possible to identify flexible region of coiled coil only from the hydrophobic features of amino acid sequences. To evaluate the result of prediction, we directly analyzed the bend positions of myosin rod using atomic force microscopy (AFM) and compare these results with prediction. The results of AFM imaging showed four main flexible resions in a single myosin rod and of the 17 possible fragile points predicted, 16 were located in the four experimental bending regions. As a result, our prediction showed a very good correlation to the four flexible regions derived from that of skeletal myosin.

\section{TA2-04 非同期型昆虫飛翔筋のカルシウムによる張力発生と伸張による張 力発生は異なる温度依存性をもつ}

Calcium-activated and stretch-activated forces have different temperature dependence in asynchronous flight muscle of insect

Hiroyuki Iwamoto (1) ((1) SPring-8, JASRI)

Besides the normal calcium-induced activation, insect flight muscle (IFM) is also activated by stretch. This stretch activation is considered essential for highfrequency wingbeat of asynchronous insect flight muscle, but its molecular mechanism remains unclear. To further address this issue, we examined the temperature dependence of calcium-activated (CA) and stretch-activated (SA) forces of IFM. The IFM of a flying bumblebee is endothermically maintained at $\sim 42^{\circ} \mathrm{C}$ regardless of ambient temperature. Isolated, skinned IFM fibers of bumblebee still develops substantial CA force of $\sim 80 \mathrm{KPa}$ and also SA force at $\sim 20^{\circ} \mathrm{C}$, saturating $\left[\mathrm{Ca}^{2+}\right]$. If the temperature is lowered to $\sim 5^{\circ} \mathrm{C}$, the fibers develop little CA force. Surprisingly, lowering temperature did not inhibit SA force. There is a critical temperature of $\mathrm{CA}$ force development at around $15^{\circ} \mathrm{C}$, while the SA force has bell-shaped temperature dependence with optimal temperatures at $10 \sim 20^{\circ} \mathrm{C}$. These observations suggest that the inhibition of $\mathrm{CA}$ force at low temperatures is not due to the impaired function of myosin, but it is an issue of regulation. To examine how the thin-filament regulatory system is implicated in this dual temperature sensitivity, the behavior of thin-filament-based X-ray reflections is currently being recorded from calcium-activated and cyclically stretched IFM fibers at low and high temperatures.

\section{TA2-05 中性子スピンエコー法によるアクチン分子の運動の測定} Measurements of motions of actin by neutron spin-echo spectroscopy

Satoru Fujiwara (1), Fumiko Matsumoto (1), Hiroshi Nakagawa (1), Hitoshi Endo (2), Toshiro Oda (3) ((1) Quantum Beam Science Directorate, Japan Atomic Energy Agency: (2) Inst. Solid State Phys., Univ. Tokyo: (3) RIKENSPring-8 center, RIKEN Harima Inst.)

F-actin plays important roles in various functions related to cell motility. Such multiple functions of $\mathrm{F}$-actin originate from flexibility of F-actin that makes interactions with various actin-binding proteins possible. To understand flexibility of F-actin and thereby its multiple functions, it is important to understand dynamic properties of $\mathrm{F}$-actin at various levels from internal dynamics of the monomers through relative motions between the monomers to large-scale motions of F-actin. As one of the ongoing projects towards this ultimate purpose, we employed neutron spin-echo (NSE) spectroscopy to investigate the motions of Factin on pico-to-nanosecond timescales and nm spatial scales, which correspond to the scales on which motions such as diffusions of the proteins, domain motions of the protein, and relative motions of the subunits within the macromolecular complex occur. We carried out the NSE experiments of F-actin and G-actin with 